\title{
ANALYSIS OF $2^{4}$ FACTORIAL DESIGN FOR A CONTROLLABLE M/G/1 SYSTEM
}

\author{
Jau-Chuan $\mathrm{Ke}^{1}$, Ming Yang $\mathrm{Ko}^{2}$ and Kuo-Ching Chiou ${ }^{3}$ \\ ${ }^{1}$ Department of Applied Statistics, National Taichung Institute of Technology, \\ Taichung 404, Taiwan, R.O.C. E-mail:\{jauchuan@ntit.edu.tw \\ ${ }^{2}$ Department of Accounting and Statistics, National Taichung Institute of \\ Technology, Taichung 404, Taiwan, R.O.C. E-mail: \{myko@ntit.edu.tw \\ ${ }^{3}$ Department of Finance, Chaoyang University of Technology, \\ E-mail: \{kcchiou@mail.cyut.edu.tw $\}$
}

\begin{abstract}
This paper presents a sensitivity investigation of the expected busy period for a controllable M/G/1 queueing system by means of a factorial design statistical analysis. We studies the effect of four important factors (parameters) that influence the expected busy period of an M/G/1 system, in which the server operates $<\mathrm{p}, \mathrm{N}>$-policy in his idle period. A $2^{4}$ factorial experimental design is used to evaluate the sensitivity analysis of parameters on the expected busy period of a controllable M/G/1 queue. Based on the analysis of variance, we find the main effect and interaction effect of the significant factors on the system characteristics.
\end{abstract}

Keywords- ANOVA, Busy period, Queue, Sensitivity analysis.

\section{INTRODUCTION}

In this paper, we conduct an experiment study for the sensitivity analysis of parameter patterns on the expected busy period for a controllable M/G/1 queueing system. The arrival of customers follows a Poisson process with parameter $\lambda$. Arriving customers at the system form a single waiting line and are served in the order of their arrivals. There is a single server that provides his service for the arriving customers and operates $\langle\mathrm{p}, \mathrm{N}\rangle$ policy in his idle period. The concept of a $<\mathrm{p}, \mathrm{N}>$-policy in the controllable queueing system was first introduced by Feinberg and Kim [1]. An operating policy is called the $<\mathrm{p}, \mathrm{N}>$-policy if it prescribes the following conditions: (i) turn the server off when the system is empty, (ii) turn the server on if there are $\mathrm{N}(\mathrm{N} \geq 1)$ or more customers are present, (iii) if the server is off and the number of customers in the system reaches $\mathrm{N}$, turn the server on with probability $p$ and leave the server off with probability (1-p), and (iv) do not turn the server at other epochs.

The related statistical studies of queueing problems mostly concentrated on statistical inferences of parameters or system characteristics. An overview of literature on the statistical analysis of several queueing systems was provided by Dshalalow [2]. Rodrigues and Leite [3] applied Bayesian analysis to construct confidence intervals of an $\mathrm{M} / \mathrm{M} / 1$ queue. Huang and Brill [4] built the minimum variance unbiased estimator and the maximum likelihood estimator of a collection of $n$ independent $\mathrm{M} / \mathrm{G} / \mathrm{c} / \mathrm{c}$ queues. Wang et al. [5] presented the maximum likelihood estimates and confidence intervals of an $\mathrm{M} / \mathrm{M} / \mathrm{R} / \mathrm{N}$ queue with balking and heterogeneous servers. Chu and $\mathrm{Ke}$ [6] examined the statistical behavior of the mean response time for the ordinary M/G/1 queueing system using bootstrapping simulation. Recently, Ke and Chu [7] and 
Chu and $\mathrm{Ke}$ [8] gave a simulated analysis and comparative analysis of an ordinary G/G/1 queueing system based on a non-parametric statistical knowledge. Existing research works, including those mentioned above, most focused on the estimations or hypothesis testing of system parameters and other system characteristics. So far very few authors have studied the sensitivity investigations of parameters on the system characteristics of a queueing system using statistical analysis. As for the sensitivity analysis of queueing problems, most researchers examined the effect of changes in the specific values of the system parameters on the system characteristics or other objective functions (see Ke and Wang [9], Wang et al. [10] and etc.). They rarely dealt with the interaction effect among parameter distributions on the system characteristics or other objective functions. Therefore, motivated by the above finding this paper is to develop a factorial design statistical analysis to investigate the main effect and interaction effect of parameters on the expected busy period for a controllable $\mathrm{M} / \mathrm{G} / 1$ queueing system. A more detailed treatment of factorial design can be found in specific literature [11].

This remainder of this paper is organized as follows. In section 2, some analytic results related to a controllable $\mathrm{M} / \mathrm{G} / 1$ queueing system is briefly reviewed. In section 3 , we describe the design of experiment used evaluate the sensitivity of the expected busy period for the controllable queueing system. In Section 4, we report the experimental results of our simulation. Finally, some conclusions are presented in Section 5.

\section{ON M/G/1 SYSTEM WITH $<\mathrm{p}, \mathrm{N}>$ POLICY}

Let $U$ and $V$ represent interarrival time and service time for the test customer of an $\mathrm{M} / \mathrm{G} / 1$ queueing system with $\langle\mathrm{p}, \mathrm{N}>$ policy, where $U$ follows an exponential distribution with mean $1 / \lambda$ and is independent of general distribution $V$. By similar arguments of Feinberg and Kim [1], we easily obtain the expected busy period of the controllable system given by

$$
\beta=\frac{(N+1-p) E[V]}{1-\lambda E[V]},
$$

where $E[V]$ represents mean service time.

Estimating the expected busy period $\beta$

Assume that $U_{1}, U_{2}, \cdots, U_{n}$ is a random sample from $U$ with distribution function $F(\cdot)$ and let $V_{1}, V_{2}, \cdots, V_{n}$ is a random sample from $V$. We use $\left(U_{i}, V_{i}\right)$ to represent interarrival time and service time for the $i$ th customer of the controllable M/G/1 queueing system. Let $\bar{U}$ be the sample mean of $U_{1}, U_{2}, \ldots, U_{n}$; and $\bar{V}$ the sample mean of $V_{1}, V_{2}, \ldots, V_{n}$ is a random sample of $V$. According to Strong Law of Large Numbers (see Roussas [12], p.196), $\bar{U}$ and $\bar{V}$ are strong consistent sample estimators of $1 / \lambda, E[U]$, respectively. From statistics knowledge (Roussas [12]), a good estimator of $\beta$ is given by

$$
\hat{\beta}=\frac{(N+1-p) \bar{U} \bar{V}}{\bar{U}-\bar{V}} .
$$

To study the main effect and interaction effect of parameter distributions on the 
expected busy period, we perform analysis of variance on the expected busy period by means of the $2^{4}$ factorial design.

\section{3. $2^{4}$ FACTORIAL DESIGN MODEL}

To explore the effect of arrival rate $(\lambda)$, control probability $(p)$, control threshold $(N)$ and queueing types on the expected busy period of a controllable M/G/1 queueing system with $<\mathrm{p}, \mathrm{N}>$-policy, we use a $2 \times 2 \times 2 \times 2$ factorial experimental design which results in a total of 16 treatments. The $2^{4}$ factorial design model is given by

$$
\begin{aligned}
& y_{i j k l}=\mu+\alpha_{i}+\beta_{j}+\gamma_{k}+\tau_{l}+(\alpha \beta)_{i j}+(\alpha \gamma)_{i k}+(\alpha \tau)_{i l}+(\beta \gamma)_{j k}+(\beta \tau)_{j l}+(\gamma \tau)_{k l}+(\alpha \beta \gamma)_{i j k}+(\alpha \beta \tau)_{j i l}+(\alpha \gamma \tau)_{i k l}+(\beta \gamma \tau)_{j k l}+(\alpha \beta \gamma \tau)_{j j k l}+\varepsilon_{i j k l r}, \\
& \text { for } i, j, k, l=1,2 \text { and } \mathrm{r}=1,2,3 \text {, where } \quad \varepsilon_{i j k l r} \sim N\left(0, \sigma^{2}\right) .
\end{aligned}
$$

The selected levels for four factors are as follows: arrival rate $(\lambda=0.2$ and 0.8$)$, control probability $(\mathrm{p}=0.2$ and 0.8$)$, control threshold $(\mathrm{N}=5$ and 15$)$ and queueing types $\left(\mathrm{M} / \mathrm{E}_{4} / 1\right.$ queue and $\mathrm{M} / \mathrm{H}_{4} / 1$ queue $)$, where $E[V]=1.0$. We set up levels of arrival rate as low intensity $(\lambda=0.2)$ and high intensity $(\lambda=0.8)$; levels of control probability as low $(\mathrm{p}=0.2)$ and high $(\mathrm{p}=0.8)$; and levels of control threshold as low $(\mathrm{N}=5)$ and high $(\mathrm{N}=15)$ in order to consider various combinations of parameter distributions. For each combination, three replicates of a sample size $n=100$ each are conducted, where random samples of interarrival times $\left(u_{1}, u_{2}, \ldots, u_{n}\right)$ and service times $\left(v_{1}, v_{2}, \ldots, v_{n}\right)$ are drawn from $U$ and $V$, respectively. That is, we obtain three replications of the expected busy period in the system from 100 arrivals and service times in various parameter setting. The design experimental worksheet is shown in Table 1. They are used to find the significant factors based on the analysis of variance (ANOVA) for the expected busy period. Results of ANOVA are obtained at 5\% significance level. The goal of the above experiment is to evaluate the sensitivity analysis of system parameters on the expected busy period.

Table 1. Experimental worksheet and experimental results

\begin{tabular}{|cccccc|}
\hline $\begin{array}{c}\text { experimental } \\
\text { order }\end{array}$ & $\begin{array}{c}\text { Control } \\
\text { threshold (N) }\end{array}$ & $\begin{array}{c}\text { Control } \\
\text { probability }(\mathrm{p})\end{array}$ & $\begin{array}{c}\text { Arrival } \\
\text { rate }(\lambda)\end{array}$ & Type & Observation \\
\hline 1 & 1 & 1 & -1 & 1 & 1.725738 \\
\hline 2 & 1 & -1 & 1 & 1 & 15.441305 \\
\hline 3 & 1 & 1 & 1 & 1 & 13.715429 \\
\hline 4 & -1 & 1 & 1 & -1 & 2.679785 \\
\hline 5 & 1 & 1 & -1 & -1 & 1.725913 \\
\hline 6 & 1 & -1 & -1 & -1 & 1.650349 \\
\hline 7 & 1 & 1 & 1 & 1 & 10.521979 \\
\hline 8 & -1 & -1 & 1 & 1 & 3.161943 \\
\hline 9 & -1 & 1 & -1 & -1 & 0.563080 \\
\hline 10 & -1 & -1 & 1 & -1 & 4.052290 \\
\hline 11 & 1 & 1 & -1 & -1 & 1.574526 \\
\hline 12 & -1 & 1 & -1 & -1 & 0.591416 \\
\hline 13 & 1 & 1 & 1 & -1 & 19.933934 \\
\hline
\end{tabular}




\begin{tabular}{|c|c|c|c|c|c|}
\hline 14 & -1 & 1 & -1 & 1 & 0.581632 \\
\hline 15 & -1 & -1 & -1 & 1 & 0.676497 \\
\hline 16 & -1 & 1 & -1 & 1 & 0.639094 \\
\hline 17 & 1 & -1 & 1 & 1 & 10.695994 \\
\hline 18 & -1 & 1 & 1 & -1 & 8.389053 \\
\hline 19 & -1 & 1 & 1 & 1 & 3.124714 \\
\hline 20 & 1 & 1 & -1 & 1 & 1.801016 \\
\hline 21 & -1 & -1 & 1 & -1 & 5.959114 \\
\hline 22 & -1 & -1 & -1 & 1 & 0.635373 \\
\hline 23 & -1 & -1 & -1 & -1 & 0.602029 \\
\hline 24 & 1 & -1 & -1 & 1 & 1.902770 \\
\hline 25 & 1 & 1 & 1 & 1 & 20.036520 \\
\hline 26 & 1 & -1 & 1 & -1 & 27.261812 \\
\hline 27 & 1 & 1 & -1 & 1 & 1.636637 \\
\hline 28 & 1 & -1 & -1 & 1 & 1.545616 \\
\hline 29 & 1 & 1 & -1 & -1 & 1.621868 \\
\hline 30 & -1 & -1 & 1 & 1 & 2.460842 \\
\hline 31 & 1 & 1 & 1 & -1 & 7.383641 \\
\hline 32 & 1 & -1 & 1 & -1 & 7.634554 \\
\hline 33 & 1 & 1 & 1 & -1 & 11.482478 \\
\hline 34 & -1 & -1 & -1 & 1 & 0.702448 \\
\hline 35 & 1 & -1 & 1 & -1 & 11.023537 \\
\hline 36 & -1 & 1 & -1 & -1 & 0.613063 \\
\hline 37 & -1 & -1 & -1 & -1 & 0.599661 \\
\hline 38 & 1 & -1 & -1 & 1 & 1.690808 \\
\hline 39 & -1 & 1 & 1 & -1 & 3.326087 \\
\hline 40 & -1 & 1 & -1 & 1 & 0.570840 \\
\hline 41 & -1 & 1 & 1 & 1 & 7.512031 \\
\hline 42 & 1 & -1 & 1 & 1 & 8.846204 \\
\hline 43 & 1 & -1 & -1 & -1 & 1.728183 \\
\hline 44 & -1 & -1 & 1 & 1 & 5.154371 \\
\hline 45 & 1 & -1 & -1 & -1 & 1.947580 \\
\hline 46 & -1 & -1 & 1 & -1 & 11.222003 \\
\hline 47 & -1 & 1 & 1 & 1 & 10.871766 \\
\hline 48 & -1 & -1 & -1 & -1 & 0.739204 \\
\hline
\end{tabular}

Remark: 1: high level, -1: low level.

\section{EXPERIMENTAL RESULTS AND DISCUSSIONS}

First, we assume the model (equation (3)) is adequate and the error term 
normally and independently distributed with constant variance. The test procedure is usually summarized in an analysis of variance table, as shown in Tables 2-3.

In Table 2, it shows that the main effect is significant at 5 percent, and there are no interactions between the factors. And then, in Table 3, we get the results that the only two factors $\mathrm{N}$ and $\lambda$ have a significantly effect on the expected busy period and an interaction between them occurs. The effect of $\lambda$ and $N$ (i.e., $t$ values) on the expected busy period is particularly larger and positive, which imply the high level of $\lambda$ or $\mathrm{N}$ has a larger expected busy period. That is, the expected busy period increases when $\lambda$ or $\mathrm{N}$ increases.

Table 2. Analysis of Variance

\begin{tabular}{|c|r|r|r|r|r|}
\hline $\begin{array}{c}\text { Source of } \\
\text { Variation }\end{array}$ & $\begin{array}{c}\text { Sum of } \\
\text { Squares }\end{array}$ & $\begin{array}{c}\text { Degrees } \\
\text { of } \\
\text { Freedom }\end{array}$ & $\begin{array}{c}\text { Mean } \\
\text { Square }\end{array}$ & F & p-value \\
\hline Main effect & 1115.64 & 4 & 278.91 & $19.68^{*}$ & $<0.001$ \\
\hline $\begin{array}{c}\text { 2-way } \\
\text { Interaction }\end{array}$ & 171.01 & 6 & 28.502 & 2.01 & 0.093 \\
\hline $\begin{array}{c}\text { 3-way } \\
\text { Interaction }\end{array}$ & 23.68 & 4 & 5.921 & 0.42 & 0.795 \\
\hline $\begin{array}{c}\text { 4-way } \\
\text { Interaction }\end{array}$ & 0.06 & 1 & 0.056 & 0 & 0.95 \\
\hline Residual Error & 453.46 & 32 & 14.171 & & \\
\hline Total & 1763.85 & 47 & & & \\
\hline
\end{tabular}

* Significant at 5 percent

Table 3. Estimated Effect and Coefficients for Observations

\begin{tabular}{|c|r|r|r|r|r|}
\hline Term & \multicolumn{1}{|c|}{ Effect } & \multicolumn{1}{c|}{ Coef. } & \multicolumn{1}{c|}{ SE Coef. } & \multicolumn{1}{c|}{$\mathrm{T}$} & p-value \\
\hline Constant & 5.4158 & 0.5433 & 9.97 & 0 & \\
\hline$\lambda$ & 8.4928 & 4.2464 & 0.5433 & $7.82^{*}$ & $<0.001$ \\
\hline $\mathrm{p}$ & 0.2203 & 0.1102 & 0.5433 & 0.2 & 0.841 \\
\hline $\mathrm{N}$ & 4.5458 & 2.2729 & 0.5433 & $4.18^{*}$ & $<0.001$ \\
\hline $\mathrm{Type}$ & -0.3606 & -0.1803 & 0.5433 & -0.33 & 0.742 \\
\hline $\mathrm{N}^{*} \mathrm{p}$ & -0.0711 & -0.0355 & 0.5433 & -0.07 & 0.948 \\
\hline $\mathrm{N}^{*} \lambda$ & 3.4594 & 1.7297 & 0.5433 & $3.18^{*}$ & 0.003 \\
\hline $\mathrm{N}^{*}$ Type & -0.0901 & -0.0451 & 0.5433 & -0.08 & 0.934 \\
\hline
\end{tabular}




\begin{tabular}{|c|r|r|r|r|r|}
\hline $\mathrm{p}^{*} \lambda$ & 0.285 & 0.1425 & 0.5433 & 0.26 & 0.795 \\
\hline $\mathrm{p}^{*}$ Type & 1.4316 & 0.7158 & 0.5433 & 1.32 & 0.197 \\
\hline$\lambda^{*}$ Type & -0.3732 & -0.1866 & 0.5433 & -0.34 & 0.734 \\
\hline $\mathrm{N}^{*} \mathrm{p} * \lambda$ & -0.0724 & -0.0362 & 0.5433 & -0.07 & 0.947 \\
\hline $\mathrm{N}^{*} \mathrm{p}^{*}$ Type & -0.0284 & -0.0142 & 0.5433 & -0.03 & 0.979 \\
\hline $\mathrm{N}^{*} \lambda^{*}$ Typel & -0.0865 & -0.0433 & 0.5433 & -0.08 & 0.937 \\
\hline $\mathrm{p}^{*} \lambda^{*}$ Type & 1.4001 & 0.7 & 0.5433 & 1.29 & 0.207 \\
\hline $\mathrm{N}^{*} \mathrm{p}^{*} \lambda$ Type & -0.0682 & -0.0341 & 0.5433 & -0.06 & 0.95 \\
\hline
\end{tabular}

* Significant at 5 percent

Next, we check the $2^{4}$ factorial model to see whether the error term for the response (the expected busy period) is adequate or not. The plot of residuals versus fitted values, shown in Fig.1, is disturbing since the outward-opening funnel shape indicates that the constant variance assumption is not satisfied (i.e., variance is non-homogeneous). A normal probability plot and a dot diagram of these residuals are displayed in Fig. 2, it shows that the error term is not normal, because the dot diagram is not approximate a straight line.

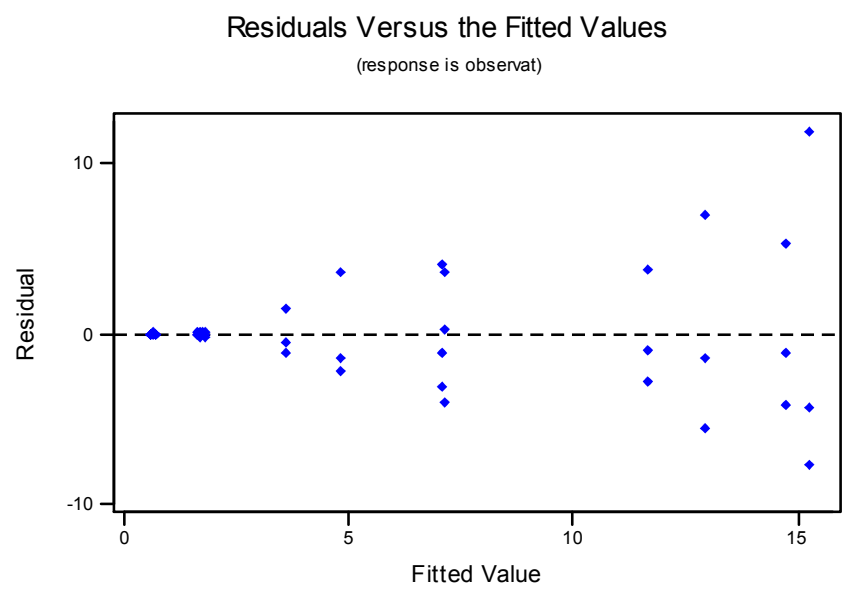

Fig. 1. Plot of residuals versus fitted values 


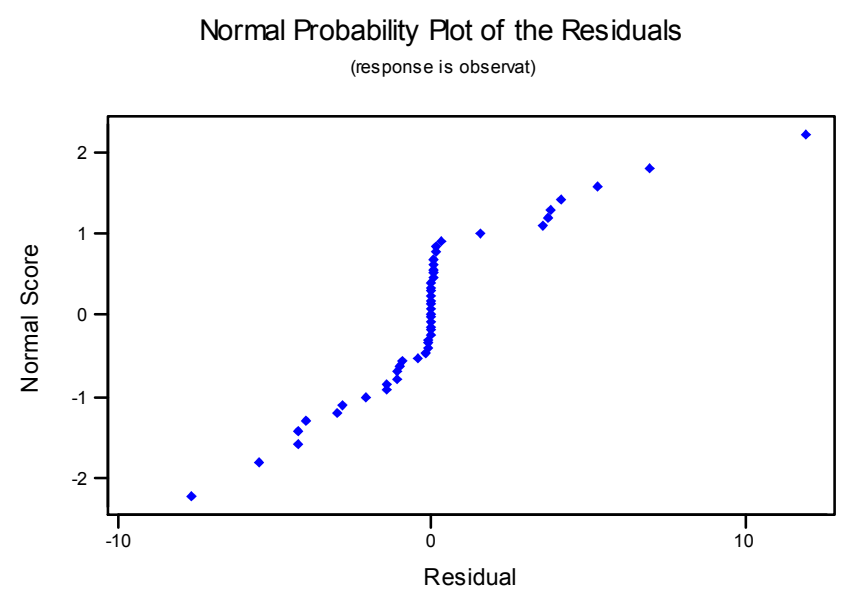

Fig. 2. Normal probability plot and a dot diagram

Because the error variance may be non-homogeneous (see Fig.1), Thus we investigate the possibility of using a variance-stabilizing transformation on the data. We try the inverse transformation $y^{*}=1 / y$ to improve the homogeneity of the error variances. And then, the Fig. 3 reveals no pattern exists and the homogeneity of the error variance is satisfied. 4 , the p-value is 0.701 by Anderson-Darling test and the dot diagram is approximate a straight line. Therefore, the results are displayed the error term satisfies the normality assumption under significant level 0.05 . A plot of these residuals versus order of data collection is shown in Fig. 5. There is no reason to suspect any violation of the independence or constant variance assumptions of error term. From the above listed, we conclude the inverse transformation is appropriate. The assumptions of error term in equation (3) appear to be satisfied for $y^{*}$ and we would conclude the test in Tables 4-5 is valid.

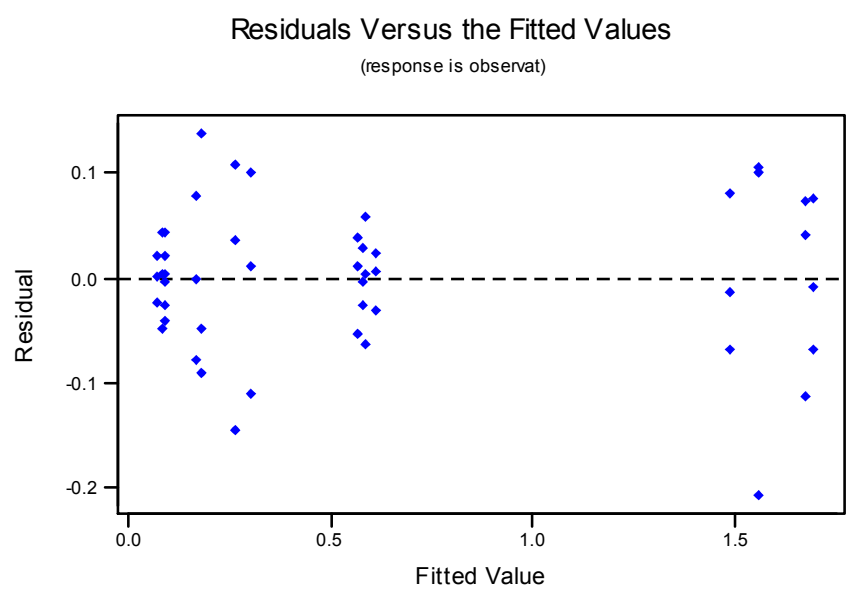

Fig. 3. Plot of residuals versus fitted values 
Normal Probability Plot

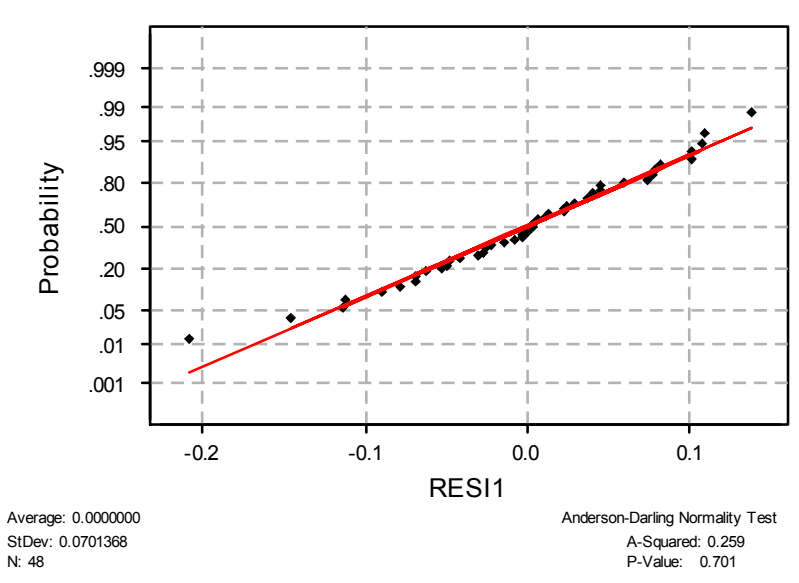

Fig. 4. Normal probability plot

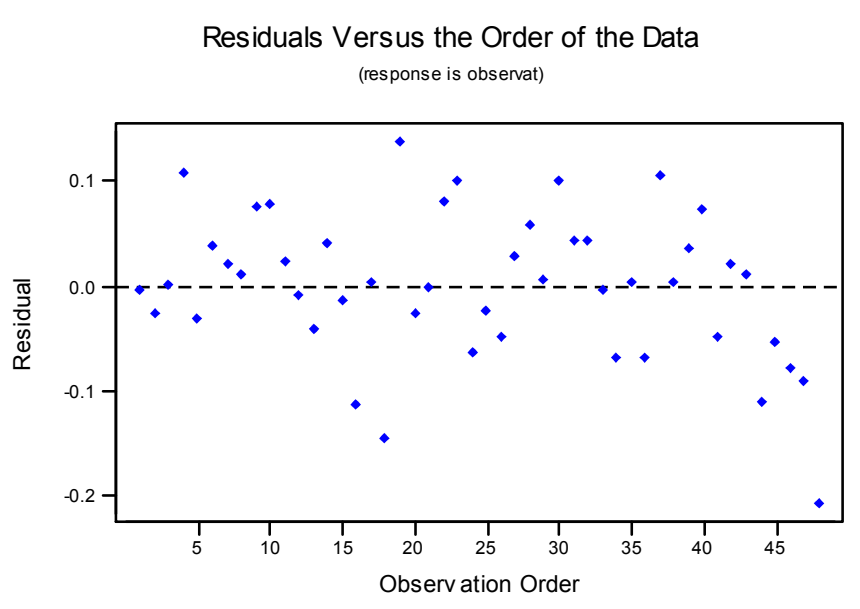

Fig. 5. Residuals versus the order of the data

In Table 4, it shows that main effect and 2-way interaction are significant at 5 percent. And then, we find from Table 5 that there is a two-way interaction between factors $N$ and $\lambda$, and $p$ and $\lambda$. One can more convince the results of Table 3 that the two factors $\mathrm{N}$ and $\lambda$ have a significantly interaction effect on the expected busy period.

Table 4. Analysis of Variance

\begin{tabular}{|c|c|c|c|c|c|}
\hline $\begin{array}{c}\text { Source of } \\
\text { Variation }\end{array}$ & $\begin{array}{c}\text { Sum of } \\
\text { Squares }\end{array}$ & $\begin{array}{c}\text { Degrees } \\
\text { of } \\
\text { Freedom }\end{array}$ & $\begin{array}{c}\text { Mean } \\
\text { Square }\end{array}$ & F & -value \\
\hline Main effect & 14.6926 & 4 & 3.67316 & $508.39^{*}$ & $<0.001$ \\
\hline
\end{tabular}




\begin{tabular}{|c|c|c|c|c|c|}
\hline $\begin{array}{c}\text { 2-way } \\
\text { Interaction }\end{array}$ & 2.3624 & 6 & 0.39373 & $54.5^{*}$ & $<0.001$ \\
\hline $\begin{array}{c}\text { 3-way } \\
\text { Interaction }\end{array}$ & 0.0341 & 4 & 0.00851 & 1.18 & 0.339 \\
\hline $\begin{array}{c}\text { 4-way } \\
\text { Interaction }\end{array}$ & 0.0164 & 1 & 0.01643 & 2.27 & 0.141 \\
\hline Residual Error & 0.2312 & 32 & 0.00723 & & \\
\hline Total & 17.3367 & 47 & & & \\
\hline
\end{tabular}

* Significant at 5 percent

Table 5. Estimated Effect and Coefficients for Observations

\begin{tabular}{|c|c|c|c|c|c|}
\hline Term & Effect & Coef. & SE Coef. & $\mathrm{T}$ & $\mathrm{p}$-value \\
\hline Constant & & 0.6273 & 0.01227 & $51.13^{*}$ & $<0.001$ \\
\hline$\lambda$ & -0.9396 & -0.4698 & 0.01227 & $-38.29^{*}$ & $<0.001$ \\
\hline $\mathrm{p}$ & 0.0404 & 0.0202 & 0.01227 & 1.65 & 0.109 \\
\hline $\mathrm{N}$ & -0.5829 & -0.2915 & 0.01227 & $-23.76^{*}$ & $<0.001$ \\
\hline Type & -0.0068 & -0.0034 & 0.01227 & -0.28 & 0.782 \\
\hline $\mathrm{N}^{*} \mathrm{p}$ & -0.0341 & -0.0171 & 0.01227 & -1.39 & 0.174 \\
\hline $\mathrm{N} * \lambda$ & 0.4381 & 0.219 & 0.01227 & $17.85^{*}$ & $<0.001$ \\
\hline $\mathrm{N}^{*}$ Type & 0.0017 & 0.0009 & 0.01227 & 0.07 & 0.944 \\
\hline $\mathrm{p} * \lambda$ & -0.0505 & -0.0253 & 0.01227 & $-2.06^{*}$ & 0.048 \\
\hline $\mathrm{p}^{*}$ Type & -0.0307 & -0.0153 & 0.01227 & -1.25 & 0.22 \\
\hline$\lambda^{*}$ Type & 0.0171 & 0.0086 & 0.01227 & 0.7 & 0.491 \\
\hline $\mathrm{N}^{*} \mathrm{p} * \lambda$ & 0.0377 & 0.0189 & 0.01227 & 1.54 & 0.134 \\
\hline $\mathrm{N}^{*} \mathrm{p}$ Type & 0.0124 & 0.0062 & 0.01227 & 0.51 & 0.616 \\
\hline $\mathrm{N}^{*} \lambda *$ Type & -0.019 & -0.0095 & 0.01227 & -0.77 & 0.445 \\
\hline $\mathrm{p}^{*} \lambda *$ Type & -0.03 & -0.015 & 0.01227 & -1.22 & 0.23 \\
\hline $\mathrm{N}^{*} \mathrm{p}^{*} \lambda *$ Type & 0.037 & 0.0185 & 0.01227 & 1.51 & 0.141 \\
\hline
\end{tabular}

* Significant at 5 percent

Based on the above results from the factorial design statistical analysis, we conclude that

- The two-way interaction effect of $\mathrm{N}$ and $\lambda$ has a significant impact on the expected busy period. That is, The effect of the level of control threshold $(\mathrm{N})$ depends on the arrival rate $(\lambda)$. There also exists an interaction for $p$ with $\lambda$. That is, the two parameters act dependently (not additive).

- The effect of queueing type does not have a significant impact on the expected 
busy period

\section{CONCLUSIONS}

In this paper, we performed the sensitivity of the expected busy period under 16 combinations of various levels of arrival rate $(\lambda)$, control probability (p), control threshold $(\mathrm{N})$ and queueing types (Type). Based on the factorial design statistical analysis, we found that a two-way interaction is presented among $\mathrm{N}, \mathrm{p}$, and $\lambda$. In a word, the significant $\mathrm{N} \lambda(\mathrm{p} \lambda)$ interaction implies that expected busy period to arrival rate depends on which control threshold (control probability) is used. That is, $\mathrm{N}$ with $\lambda$ ( $\mathrm{p}$ with $\lambda$ ) jointly affects the expected busy period.

\section{REFERENCES}

1.E. A. Feinberg and D. J. Kim, Bicriterion optimization of an M/G/1 queue with a removable server. Probability in the Engineering and Informational Sciences 10, 57-73, 1996.

2.J. H. Dshalalow, Frontiers in Queueing: Models and Applications in Science and Engineering. CRC Press, Inc. 1997.

3.J. Rodrigues and J. G. Leite, A note on Bayesian analysis in $\mathrm{M} / \mathrm{M} / 1$ queues derived from confidence intervals. Statistics 31, 35-42, 1998.

4.M. L. Huang and $P$. Brill, On estimation in $\mathrm{M} / \mathrm{G} / \mathrm{c} / \mathrm{c}$ queues. International Transactions in Operations Research 8, 647-657, 2001.

5.K.-H. Wang, S.-C. Chen and J.-C. Ke, Maximum likelihood estimates and confidence intervals of an $\mathrm{M} / \mathrm{M} / \mathrm{R} / \mathrm{N}$ queue with balking and heterogeneous servers. RAIRO - Operations Research 38 , 227-242, 2004.

6.Y.-K. Chu and J.-C. Ke, Confidence intervals of mean response time for an M/G/1queueing system: Bootstrap simulation. Applied Mathematics and Computation 180, 255-263, 2006.

7.J.-C. Ke and Y.-K. Chu, Nonparametric and simulated analysis of intensity for a queueing system. Applied Mathematics and Computation 183, 1280-1291, 2006.

8.Y.-K. Chu and J.-C. Ke, Mean response time for a G/G/1 queueing system: Simulated computation. Applied Mathematics and Computation, 186(1), 772-779, 2007.

9.J.-C. Ke and K.-H. Wang, Analysis of operating characteristics for the heterogeneous batch arrival queue with server startup and breakdowns. RAIRO Operations Research 37, 157-178, 2003.

10.K.-H. Wang, J.-B. Ke and J.-C. Ke, Profit analysis of the M/M/R machine repair problem with balking, reneging, and standby switching failures. Computers and Operations Research 34(3), 835-847, 2007.

11.D. C. Montgomery, Design and Analysis of Experiments, 4th edition, John Wiley \& Sons, New York, 1997.

12.G. G. Roussas, A course in Mathematical Statistics. $2^{\text {nd }}$ edition, Academic Press, 1997. 